\title{
Insect proteins as a potential source of antimicrobial peptides in livestock production. A review
}

\author{
A. Józefiak ${ }^{1,3}$ and R.M. Engberg ${ }^{2}$ \\ 1 Poznań University of Life Sciences, Institute of Veterinary Sciences \\ Wołyńska 35, 60-637 Poznań, Poland \\ ${ }^{2}$ Aarhus University, Department of Animal Science \\ Blichers Allé 20, 8830 Tjele, Denmark
}

KEY WORDS: insect AMPs, antimicrobial activity, defensins, bacterial resistance, dietary supplementation, livestock production

Received: 18 October 2016

Revised: 16 February 2017

Accepted: $\quad 15$ May 2017

${ }^{3}$ Corresponding author:

e-mail: agata.jozefiak@up.poznan.pl

\begin{abstract}
Together with the extraction of first insect antimicrobial protein (AMP) from the pupae of the giant silk moths Hyalophora cecropia the antibacterial activity of insects was observed for the first time in 1980. Practically, AMPs are small, cationic proteins that exhibit activity against bacteria, fungi as well as certain parasites and viruses. It is known that in addition to their antimicrobial effect, they boost host specific innate immune responses and exert selective immunomodulatory effects involved in angiogenesis and wound healing. More than 1,500 proteins with antimicrobial activity have been identified in different organisms, including plants, fungi, bacteria and animals. Insects are a primary source of AMPs which are considered as not resulting in the development of natural bacterial resistance. In general, they are characterized as heat-stable with no adverse effects on eukaryotic cells. These characteristics contribute to the potential use of these proteins in human and veterinary medicine and in animal nutrition. Depending on their mode of action, insect AMPs may be applied as single peptides, as a complex of different AMPs and as an active fraction of insect proteins in the nutrition of different livestock. The great potential for the use of AMPs in animal production is primarily associated with the growing problem of antibiotics resistance, which has triggered the search for alternatives to antibiotics in livestock production. The review presents the current knowledge of insect AMPs, their chemical structure and mode of action with focus on their potential use in agriculture and livestock production.
\end{abstract}

\section{Introduction}

Antibiotics have been used for over 50 years in animal production for treatment of infectious diseases and as growth stimulators. However, the misuse of antibiotics has caused problems primarily related to the development of bacterial antibiotic resistance.

Also, the possible accumulation of drug residues in animal products is risky for consumers and likewise contributes to the development of bacterial antibiotic resistance. These factors have resulted in a global trend to restrict the use of antibiotics in the feed industry, agriculture and veterinary medicine (Landers et al., 2012; Coyne et al., 2016). The search for alternatives to antibiotics is an urgent challenge for animal production as the maintenance of production performance as well as animal health and welfare has to be addressed adequately. 
Insects at all life stages are rich sources of protein, fat and many other important nutrients (Bovera et al., 2016). Reviews on the nutritive value of different insects and their meals including black soldier fly larvae, housefly maggot and pupae, mealworms, silkworm pupae, as well as locusts, grasshoppers and crickets demonstrate their potential application as an alternative protein source in the nutrition of different livestock species (Makkar et al., 2014; SánchezMuros et al., 2014; Józefiak et al., 2016). However, little is known about their possible secondary effects which can be related to a wide range of small peptides known as antimicrobial peptides (AMPs).

The use of AMPs may be a promising alternative to antibiotics (Li et al., 2012; Xiao et al., 2013a,b, 2015a,b; Yoon et al., 2013, 2014; Yi et al., 2014; Wang et al., 2016). The interest in insect AMPs is based on the knowledge from ancient times, where different insects were used in the treatment of a number of different ailments (Table 1). Habouring approximately 1.5 to 3 million different species, insects are a significant potential source of AMPs and knowledge on their antimicrobial effects is continuously increasing. The purpose of this review is to discuss the use of insects as a source of AMPs providing an alternative to antibiotics in livestock production. The discussion covers experience from ancient medicine, the current knowledge of insect AMPs, their mode of action, possible mechanisms of bacterial resistance and possible applications including the supplementation of animal diets.

\section{Insects as a treatment from ancient times}

Insects are known as vectors of a wide range of animal and human parasites causing such diseases as malaria, dengue and yellow fever. Paradoxically, they are also a source of different natural substances which can be employed in the development of natural bioactive compounds used for medical, veterinary and agricultural purposes. Insect toxins belong to compounds having a large number of molecules with biological activities, acting as pain-killers and drugs for neurologic and autoimmune diseases including arthritis and rheumatism, and even for cancer therapy (El-Tantawy, 2015).

Insects have been widely used in traditional medicine in many parts of the world. In Chinese medicine, the beneficial effect of insects on different ailments has been known for over 3,000 years. Around 300 insect species are used to produce 1,700 traditional Chinese medicaments (Ratcliffe et al., 2011). Among insect species known in ancient time medicine are ants, whose jaws were used in a surgery as staples for stitching wounds (Schiappa and Van Hee, 2012). Additionally, some ants produce substances that promote wound healing. The most studied application, however, is the use of maggots - larvae of the housefly. Maggots eat necrotic tissues and contribute to the process of wound healing via a number of mechanisms. After ingestion of the necrotic tissue, their secretions promote fibroblast aggregation and tissue repairment, and finally they release antimicrobial peptides which inhibit bacterial growth in the wound (Bulet et al., 2004; Andersen et al., 2010; Ratcliffe et al., 2011).

The ancient medical application of insects is still explored. For example, the dried biomass of blister beetles (Mylabris phalerata and M. cichorii) containing cantharidin has been used in Chinese traditional medicine for the treatment of cancer for over 2,000 years, and studies are currently being conducted in this area (Ratcliffe et al., 2011). Cantharidin has been prescribed for numerous diseases including rabies, oedema, warts and impotence (Ratcliffe et al., 2011). It has been shown that cantharidin, or its derivatives, can destroy a variety of tumor cells in vitro and in animal models in vivo including hepatomas, leukaemia, breast cancer, melanoma and bladder or colorectal and pancreatic cancers.

\section{Insect antimicrobial peptides (AMPs)}

In recent years, there has been increasing interest in the usage of AMPs, and much of this attention has been devoted to research regarding their impact

Table 1. Insects and insect products used in traditional medicine (Ratcliffe et al., 2011)

\begin{tabular}{ll}
\hline Examples of insects and insect products & Potential treating use \\
\hline Honey products & Wounds and infections \\
Bee, wasp and ant venom & Cancer and infections \\
Silk & Flatulence, phlegm and spasms (in Chinese medicine) \\
Cantharidin from blister beetles and other insect defensive secretions & Cancer (in Chinese medicine) \\
$\begin{array}{l}\text { Whole body extracts of several bees, wasps, flies, butterflies, moths, } \\
\quad \text { cockroaches, beetles, etc. }\end{array}$ & Viral, bacterial infections and cancer \\
Maggots & \\
Horseflies and other blood-sucking insects & Wounds, healing and infections \\
\hline
\end{tabular}


on different bacteria. It is widely known that their activity, in contrast to most classical antibiotics, does not lead to the development of natural bacterial resistance or at least the frequency of resistance is considered to be low (Narayanan et al., 2014; Chernysh et al., 2015). Most AMPs are small, cationic proteins that exhibit activity against bacteria and/or fungi, as well as certain parasites and viruses (Lee et al., 1998, 1999; Aerts et al., 2008; Ratcliffe et al., 2011; Sun et al., 2014; Yi et al., 2014). Until now, more than 1,500 proteins with antimicrobial activity have been found and identified in different organisms such as plants, fungi, bacteria and animals, however they are mainly present in insects (Yi et al., 2014).

The antibacterial activity of insects was first observed in the pupae of the giant silk moths Samia cynthia and Hyalophora cecropia (Boman et al., 1974; Faye et al., 1975), and the first insect AMP (cecropin) was extracted from the pupae of $\mathrm{H}$. cecropia in 1980 (Hultmark et al., 1980; Steiner et al., 1981). Since then, over 150 insect AMPs have been identified (Yi et al., 2014). Due to their structure and unique amino acid sequences, insect AMPs can be divided into 4 general groups: 1 . $\alpha$-helical peptides (cecropin and moricin), 2. cysteine-rich peptides (insect defensin and drosomycin), 3. proline-rich peptides (apidaecin, drosocin and lebocin) and 4. glycine-rich peptides/proteins (attacin and gloverin) (Yi et al., 2014). The smallest AMPs comprising 20-50 residues, i.e. defensins, cecropins, prolinerich peptides and attacins, have the highest activity, whereas larger ones - lower activity. Among them, gloverins $(\sim 14 \mathrm{kDa})$ and attacins $(\sim 20 \mathrm{kDa})$ exhibit the highest activity. However, some insect AMPs are enzymatically cleaved in vivo from a large precursor with no or limited antimicrobial properties (Imler and Hoffmann, 2000; Bulet et al., 2004; Bulet and Stöcklin, 2005). AMPs belonging to the same class or even subclass of compounds but derived from different insects exhibit different activity. For example cecropin A derived from silk moth (H. cecropia) shows only antibacterial activity (Gram-positive and Gram-negative), whereas cecropin A from the mosquito Anopheles gambiae shows both antibacterial (Gram-positive and Gram-negative) and antifungal activities, which result from their different size and structure affecting the affinity to different microorganisms (Bulet et al., 2004). In addition to their antimicrobial effect, it is also known that they boost specific innate immune responses and exert selective immunomodulatory effects on the host by involvement in angiogenesis and wound healing processes (Bulet et al., 2004; Żyłowska et al., 2011).
The largest group of insect AMPs consists of defensins, which have also been identified in rabbits, guinea pigs, rats, mice, cattle, sheep, goats, pigs, birds and humans. Mammalian $\alpha$-defensins have been detected in neutrophils and alveolar macrophages as well as in epithelial cells, including the female reproductive tract and in Paneth cells of small intestinal crypts of humans, rats and mice (Lehrer and Ganz, 1990; Jones and Bevins, 1992; Ouellette et al., 1999; Luenser and Ludwig, 2005). Based on the structural characteristics, defensins are classified into three families: 'classical' defensins, $\beta$-defensins and insect defensins. In general, they belong to small $(\sim 4 \mathrm{kDa})$ cationic AMPs and contain six cysteines which form three intramolecular disulfide bridges. Insect defensins are peptides consisting of 34-51 amino acids residues with six conserved cysteines. They have been identified in numerous insect species belonging to Diptera, Hymenoptera, Coleoptera, Lepidoptera, Hemiptera, Isoptera, Odonata orders (Yi et al., 2014). Currently, almost 170 defensins are known to be present in invertebrates. In insects, these peptides are produced by the cells of the fat body, as well as haemocytes from where they can easily diffuse and act systemically. The insect haemolymph gains antimicrobial properties after the insect has been wounded or after microbial infection. Insect defensins are active mainly against Gram-positive bacteria, including Micrococcus luteus, Aerococcus viridians, Bacillus megaterium, B. subtilis, B. thuringiensis and Staphylococcus aureus. Some insect defensins are also active against Gram-negative bacteria as Escherichia coli (Yi et al., 2014). Further, antifungal properties against filamentous fungi and yeast strains have been observed, e.g., termicin in Pseudacanthotermes spiniger, drosomicin in Drosophila melanogaster, heliomicin in Heliothis verescens and gallerimicin in the pupae of Galleria mellonella (Aerts et al., 2008; Żyłowska et al., 2011).

\section{Working mechanism of AMPs}

The mechanism by which AMPs exert their activity involves the destruction of the bacterial cell envelope. Most AMPs are cationic molecules which perturb the target cell membranes through the formation of ion channels or transmembrane pores and in this way destroy the bacterial cell (Duclohier, 2002; Park and Hahm, 2005). They penetrate the cell through the negatively charged particles present in the bacterial cell envelopes with which the peptide can interact (Bagnicka et al., 2011). The main targets of AMPs are lipids in bacterial cell membrane. 
The AMPs bind to anionic phospholipids and phosphate groups of lipopolysaccharides (LPS) of Gram-negative bacteria, as well as to teichoic and lipoteichoic acids composing the peptidoglycan layer of Gram-positive bacteria (Figure 1, Part I). The peptide anchors in the cytoplasmic membrane of the microorganism and changes the membrane structure which facilitates the incorporation into the phospholipid dual layer of the cytoplasmic membrane (Żyłowska et al., 2011). The efficiency of their antimicrobial activity depends on differences in the lipid composition and negative electrical potential of the target membrane. Currently, four different models of possible modes of action via bacterial cell membrane destruction are described for AMPs (Figure 1, Part II). The first (A) is the toroidal model, where the peptides aggregate to lipid monolayers and form pores, finally leading to the destruction of the bacterial cell. In the second model (B), the AMPs cover the cell membrane in a carpet-like manner.

\section{Gram-negative bacteria}

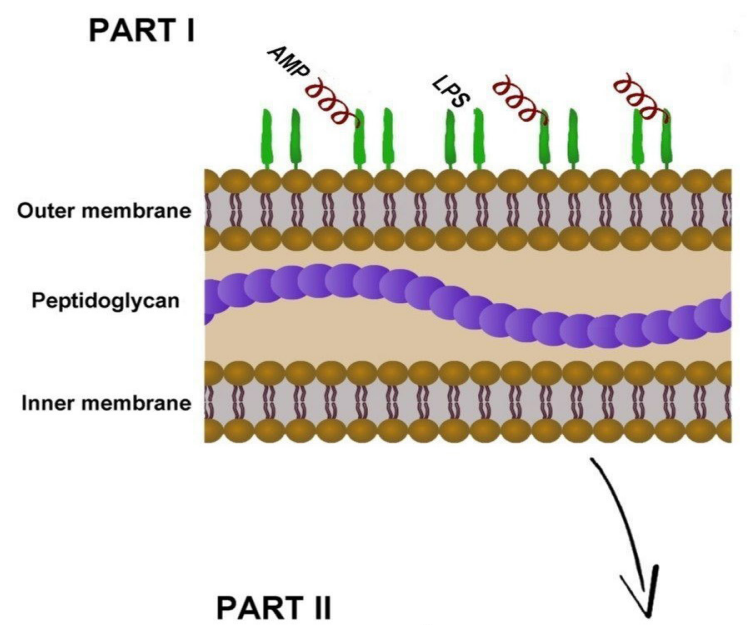

A

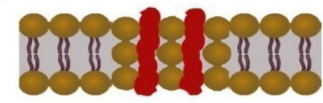

C



\section{Gram-positive bacteria}

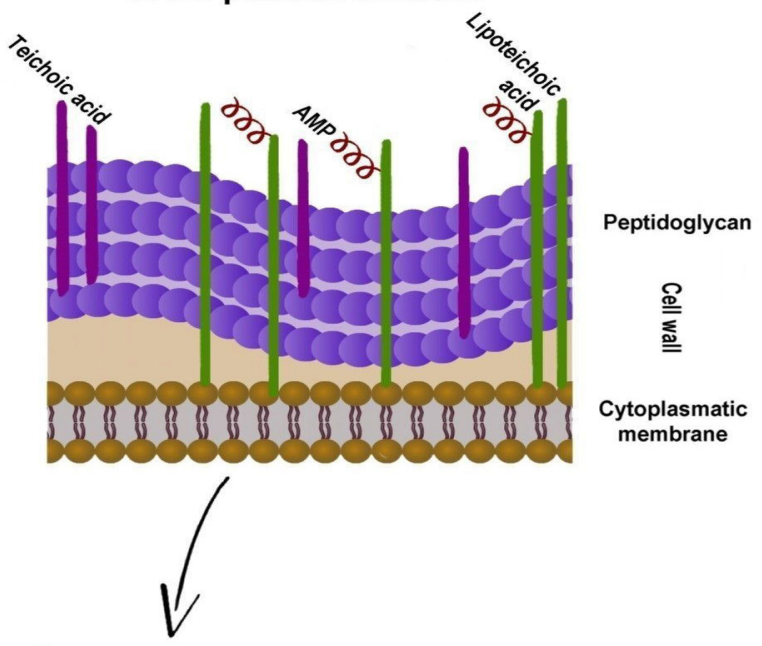

B

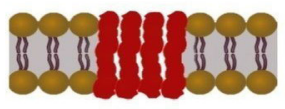

D

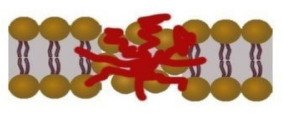

PART III
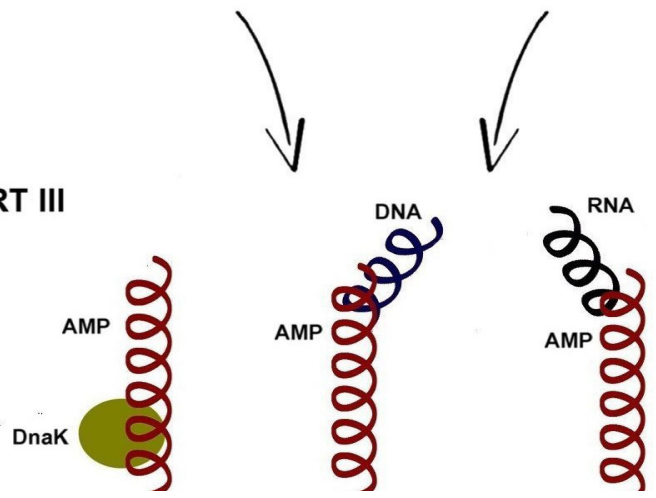

Figure 1. Working mechanism of antimicrobial peptids on bacterial cells. The figure shows different mechanisms of AMP activity on bacterial cells: binding to the bacterial cell envelope (Part I), models for the possible modes of bacterial cell membrane destruction (Part II) and the interactions of AMPs with intracellular targets (Part III). Part I: AMPs bind to the lipopolysaccharides (LPS) of Gram-negative bacteria and to teichoic and lipoteichoic acids of Gram-positive bacteria and penetrate the cell wall. Part II: Then the peptides change their structure and insert themselves into membrane forming pores leading to the destruction of the bacterial cell envelope and cell death. In the toroidal model (A), the peptides aggregate to lipid monolayers and form pores finally leading to the destruction of the bacterial cell. In the carpet-like model (B), the AMPs cover the cell membrane in a carpet-like manner. In the barrel-stave model (C), AMPs bind to the cell membrane and insert themselves into the hydrophobic core of the membrane forming a pore that causes leakage of cytoplasmic material. The 'unstructured ring pores' (D) lead to the destruction of cell membranes by creating, e.g., aggregate channels. Part III: AMPs may exert antibacterial activity by interactions with intracellular targets including heat shock protein (DnaK), DNA and RNA. 
This action requires a high AMPs concentration and causes cell membrane dissolvence, similarly to the action of a detergent. The example of AMPs acting in this way can be cecropins. The third model (C) for AMPs action is the barrel-stave model, in which peptides bind to the cell membrane and insert themselves into the hydrophobic core of the membrane, forming a pore and causing a leakage of cytoplasmic material and a decrease in membrane potential. In this way, membrane damage peptides, such as gramicidin, finally lead to the death of the cell. The fourth and the last strategy (D) is the destruction of cell membranes by creating 'unstructured ring pores', i.e. aggregate channels. Peptides do not always line up perpendicularly to the membrane, as it is on a ring, but can be anchored in the membrane at different angles (Duclohier, 2002; Żyłowska et al., 2011).

Apart from the membrane destruction, some AMPs, i.e. pyrrhocoricin, drosocin and apidaecin, may exert antibacterial activity by interactions with intracellular targets thus disrupting intracellular processes (Figure 1, Part III). These belong to short proline-rich AMPs (PrAMPs). Insect-derived PrAMPs are typically 20-35 amino acid residues long. The mechanism of action is followed by translocation into the interior of the cell. At first, peptides permeate and traverse the outer membrane and enter the periplasmic space. Then, the process looks like the stereospecific and irreversible translocation into the cytoplasm of the bacterial cell. Inside the cell, the AMPs (pyrrhocoricin and drosocin) interact with the target, which is mainly the $70 \mathrm{kDa}$ heat shock protein DnaK. They can also interfere with DNA and RNA synthesis by binding to nucleic acids (Kragol et al., 2002; Li et al., 2006; Nicolas, 2009) and have been shown to target E. coli, Klebsiella pneumoniae, Pseudomonas aeruginosa and Acinetobacter baumannii (Mattiuzzo et al., 2007; Hansen et al., 2012).

It has been suggested that AMPs exhibiting an antimicrobial effect at high concentrations act by permeabilizing/disrupting the microbial membrane, whereas AMPs, which are presumed to affect microbial viability at low to moderate concentrations, interact with intracellular targets (Nicolas, 2009).

\section{Insects providing AMPs}

One of the insects that have been intensively studied considering its unique characteristics is Hermetia illucens, an effective decomposer of different organic materials. It is believed that the immune system of $H$. illucens has developed different mechanisms to cope with pathogenic microor- ganisms it comes into contact with. Erickson et al. (2004) showed that the larvae of this insect reduce E. coli $\mathrm{O} 157: \mathrm{H} 7$ and Salmonella ser. Enteritidis in chicken manure. Although the general mechanisms of AMPs activity have been studied, only little is known about the activity of defensins and defensin-like peptides from $H$. illucens. Antibacterial properties of larvae extracts of $H$. illucens against Gram-positive S. aureus, methicillin resistant $S$. aureus (MRSA) and Gram-negative Pseudomonas aeruginosa have been demonstrated by Park et al. (2014). Methanol extracts of $H$. illucens larvae showed antibacterial effects against K. pneumoniae, Neisseria gonorrhoeae and Shigella sonnei. However, these extracts showed no antibacterial effects against Gram-positive bacteria such as B. subtilis, Streptococcus mutans and Sarcina lutea (Choi et al., 2012).

Recently, a novel AMP-defensin-like peptide 4 (DLP4) from the black soldier fly has been isolated and described (Park et al., 2015). This protein displays antimicrobial properties against Gram-positive bacteria. The minimal inhibitory concentrations (MICs) of DLP4 against MRSA, S. aureus 40881, S. aureus 12256, S. epidermidis and B. subtilis were between $0.59-1.17 \mu \mathrm{M}$. The MICs of methicillin against $S$. aureus 40881 (MRSA) and 11256 (methicillin-sensitive MSSA) were 99.40-198.80 $\mu \mathrm{M}$ and 3.11-6.21 $\mu \mathrm{M}$, respectively. The MICs of DLP4 against these strains were substantially lower $(0.59-2.34 \mu \mathrm{M})$ indicating consistent antimicrobial activity. There was no antimicrobial activity against Gram-negative bacteria (E. coli, Enterobacter aerogenes, P. aeruginosa) observed in this study, even at the highest tested concentrations of DLP4 $(4.68 \mu \mathrm{M})$. The expression of DLP4 in different tissues of the black soldier fly was shown to be the highest in the trachea and fat body (Park et al., 2015).

Antibacterial proteins have also been identified in the larvae of Musca domestica. These are cecropins and defensins, which show antibacterial activity against both Gram-positive and Gramnegative bacteria (Fu et al., 2009; Dang et al., 2010).

Proteins with antimicrobial activity have also been extracted from the larvae of the mealworm (Tenebrio molitor). An example of such protein is tenecin. It is active against Gram-positive bacteria, mainly MRSA (tenecin-1) but also against fungi (tenecin-3), which is important for the feed industry not only because of the protection of animals but, more importantly, of the feed itself (Lee et al., 1998, 1999). Insect AMPs may thus have potential for application as food preservatives. Moreover, intensive research has currently being conducted regarding the use of proteins of Tenebrio molitor in 
antineoplastic therapy. The results of studies carried out in China have shown that the insect defensins inhibit proliferation of K562 leukaemia cells. The effect of this protein was indicated by a lower number of K562 cells in the S phase. The authors believe that these peptides may be practically applicated in the future (Cheng et al., 2010).

\section{Bacterial resistance to insect AMPs}

Bacterial resistance to antimicrobials relies typically on direct drug inactivation or target site modification (mutations). An important resistance mechanism for certain classes of antimicrobials is reduced drug accumulation due to limited uptake, mainly referring to Gram-negative bacteria, or enhanced efflux mainly referring to Gram-positive bacteria (Andersson et al., 2016; Joo et al., 2016). Another mechanism is phenotypic resistance (Grampositive and Gram-negative bacteria) based on specific growth patterns such as biofilm formation (Rotem and Mor, 2009; Li et al., 2012; Andersson et al., 2016; Joo et al., 2016). However, the main problem is multidrug resistance which is costly and has generated significant problems in veterinary medicine and animal production.

In practice there are two types of bacterial resistance, i.e. intrinsic and acquired. Intrinsic resistance is the natural resistance of some bacterial species or genera to certain antibiotics thus preventing the antibiotic from entering the bacterium and exerting its action. As a result of evolution, spontaneous mutations allow the bacteria to adapt and survive in changing environments. This phenomenon can occur following repeated use of the same antibiotics. It has been shown that insect AMPs as pyrrhocoricin (PR-AMPs) deactivating intracellular microbial targets can give rise to bacterial resistence. Narayanan et al. (2014) found that spontaneous E. coli mutants resistant to pyrrhocoricin rise at a relatively high frequency.

In comparison to ampicillin, ciprofloxacin and kanamycin, which induce a 3 to 4 -fold increase of the mutation rate in bacteria, it has been shown that cationic AMPs do not increase bacterial mutation rates (Rodríguez-Rojas et al., 2014). The study was conducted using $E$. coli treated with AMPs derived from insects (cecropin A and melittin) and from humans (magainin II and pexiganan). The authors analysed 12 genes coding different stress pathways. These stress pathways increased the mutation rate only when the bacteria were treated with classical antibiotics (Rodríguez-Rojas et al., 2014), whereas the examined AMPs did not elicit bacterial stress pathways.

Horizontal transfer of bacterial resistance genes in the process of conjugation, transformation or transduction is a different mechanism of acquiring antibiotic resistance. Here, resistance genes are incorporated into plasmid DNA. This process plays a significant role in transferring antibiotic resistance genes between different bacteria species. Until now this mechanism has not been demonstrated for bacteria resisistant to insect AMPs.

Bacteria are also equipped with other mechanisms protecting them from the action of antibiotics. These involve the inactivation of the antibiotic through modification of their structure, changing the cellular target of antibiotic action, quick removal of antibiotic from the bacteria cells via the efflux pump mechanism. These mechanisms of creating bacterial antibiotic resistance could be relevant for AMPs entering the cell interior. The alteration of the cell membrane is one of the bacteria primary resistance mechanisms against AMPs (Rodríguez-Rojas et al., 2014). It was demonstrated that Gram-positive bacteria are able to modify the charge of cell wall components from anion to cation. It was reported that an increased amount of D-alanine esters in bacterial teichoic acids changed the cell wall charge, which contributed to the resistance of $S$. aureus to vancomycin and defensins (Peschel et al., 2000; Żyłowska et al., 2011). Gram-negative bacteria are capable of escaping the action of defensins by modification of their external cell membrane. This modification involves the acylation of lipid A embedded in the lipopolysaccharide layer of the outer cell membrane, thus reducing the liquidity of the membrane.

A different method of protection against defensins was developed by Salmonella Typhimurium. This bacterium impairs the action of cationic AMPs through incorporation of arabinose into phosphate groups of lipid A (Groisman et al., 1992). Passive AMP resistance through changes in lipid A, which creates a less negatively charged LPS and reduces AMP interaction with bacteria, occurs in some bacterial species such as Morganella, Providencia, Serratia and Burkholderia. This protection mechanism against defensins is also used by Proteus mirabilis, Listeria monocytogenes and L. ivanovii (Andersson et al., 2016). A different kind of protection against defensins was developed by Klebsiella pneumoniae. It involves the formation of a polysaccharide capsule providing protection against defensins (McCoy et al., 2001; Żyłowska et al., 2011). 
The most common mechanism of antibiotic resistance is enzymatic antibiotic inactivation through enzymes produced by resistant bacteria. The most studied enzymes are $\beta$-lactamases, which hydrolyse the $\mathrm{C}-\mathrm{N}$ chemical bond in the $\beta$-lactam ring of, e.g., penicillin and cephalosporin, and destroy the activity of these antibiotics. Unfortunately, bacterial enzymatic degradation of insect AMPs has not been observed yet. However, it was shown that $S$. aurerus produces staphylokinase, which induces the release of $\alpha$-defensins from multinuclear leukocytes (Jin et al., 2004). The staphylokinase binds to $\alpha$-defensins and inhibits their bactericidal action. A similar mechanism is demonstrated for group A Streptococcus which activates the extracellular secretion of protein $\mathrm{M}$ activating the secretion of the protein complement inhibitor protein (SIC), that binds $\alpha$-defensins and inactivates them (Frick et al., 2003). Morower, in $S$. Typhimurium (Guina et al., 2000) and E. coli (Stumpe et al., 1998; Andersson et al., 2016) proteases that can degrade AMPs were identified.

Efflux pumps that can act on AMPs have been identified in $S$. Typhimurium, S. aureus, Neisseria gonorrhoeae and Yersinia spp. (Shafer et al., 1998; Bengoechea and Skurnik, 2000; Andersson et al., 2016).

It has been shown that naturally occurring compounds containing insect AMP complexes have an edge over individual peptide and small molecule antibiotics with respect to the development of bacterial drug resistance (Chernysh et al., 2015). The authors extracted AMP compounds from bacterial challenged maggots of Calliphoridae fly and housefly (M. domestica). The AMP compound extracted from the blowfly (Calliphora vicina) contained three distinct families of cell membrane disrupting/ permeabilizing peptides (defensins, cecropins and diptericins), one family of proline rich peptides and several unknown antimicrobial substances. The authors analysed bacterial resistance development of E. coli, Klebsiella pneumoniae and Acinetobacter baumannii under long term selective pressure of the AMP compound compared to single reference antibiotics, e.g., cefotaxime, meropenem and polymyxin $\mathrm{B}$. The respective microorganisms readily developed bacterial resistance to the reference antibiotics, whereas no signs of resistance to the extracted AMP compound were observed. Similar results were obtained by Chernysh et al. (2015) for AMP compounds isolated from the maggots of 3 other fly species, e.g., blue blowfly (Calliphora vomitoria), green bottleneck fly (Lucilia sericata) and house fly (M. domestica).
Although the risk of bacterial resistance development against insect AMPs is regarded to be low, it seems reasonable to consider this potential risk when appliying these peptides. More research has to be done in this area.

\section{Production and expression of AMPs in insects}

For the isolation and commercial exploitation of insect AMPs, it is important to know, how insects produce them and in which tissues they are stored. The majority of insect AMPs was isolated from the haemolymph of experimentally infected insects (Dang et al., 2010; Choi et al., 2012; Park et al., 2014, 2015; Kim et al., 2016), where they are produced in the fat body and in different epithelia. The production of specific AMPs targeted at a specific pathogen may be induced by septic injury by the respective pathogen inducing quick production of antimicrobial peptides (Kim et al., 2016). However, insect AMPs can also be constitutively produced in haemocytes and are released into the haemolymph in response to infection (Fu et al., 2009). Constitutive production of AMPs may also take place in different epithelia as a local protection against different pathogens, as for example in the gastrointestinal and reproductive tract. Constitutive production of AMPs in the salivary glands presumably has an additional role, i.e. the protection of eggs from infection (Isoptera: termite) (Uvell and Engstrom, 2007; Kim et al., 2016). AMPs may be also produced constitutively in the brain of insects as shown by Lee et al. (2012) in the American cockroach (Periplaneta americana).

In response to infection, AMPs can be produced following transcription of genes encoding the respective AMP and rapid release into the haemolymph and the entire body. Further, a constitutive production of AMPs has been observed, involving the storage of AMPs in particularly haemocytes and their release into the haemolymph after immune challenge (Lamberty et al., 2001).

AMPs are mainly derived from the larval stage of insects. It has been shown that the genes encoding various peptides are rapidly induced after a septic injury. Their expression continues for at least three days. In insects with complete metamorphosis, the AMPs are rapidly and transiently synthesized by cells of the fat body (the functional equivalent of the mammalian liver) and by various epithelia. In insects nutrients they are stored in the fat body and act as a nutrient sensor, similarly to the mammalian liver and adipose tissue (Buchon et al., 2014). Most of the AMPs are produced quite massively, many 
of them reach high concentrations (i.e. $\mathrm{mgs} \cdot \mathrm{l}^{-1}$ ) (Bulet and Stöcklin, 2005). The AMPs produced by the fat body are secreted into the haemolymph, where their overall concentrations can reach values up to $0.5 \mathrm{mM}$ without exerting toxicity to the host organism. The concentration of AMPs in the insect is far higher than that required to kill most microorganisms in vitro (Bulet and Stöcklin, 2005; Choi et al., 2012; Park et al., 2015).

The constitutive expression of an antifungal AMP - termicin - was detected in haemocyte granules and in the salivary glands of the termite Pseudacanthotermes spiniger (Isoptera). The presence of a mature peptide in the salivary glands suggests a protective role for egg development (Lamberty et al., 2001). Storage of antimicrobial peptides in granular cells has already been reported for other organisms as shrimp, horseshoe crab, mussel and even humans (Lamberty et al., 2001). Constitutive expression of AMPs has also been shown in the reproductive tract of flies and their larvae, where AMPs are expressed in the epithelia of the respiratory (trachea) and gastrointestinal tracts (gut), which may reflect the different lifestyles of larvae and flies.

Park et al. (2015) showed an increasing AMP (DLP4) expression in the fat body, muscle and trachea of immunized larvae in Hermetia illucens. However, this study also showed high expression of AMPs in the whole body of non-immunized larvae, which may suggest coinsiderable constitutive AMPs production. Interestingly, one AMP can be constitutively expressed in one kind of tissue, while another is inducible in the same tissue - this indicates that different regulatory elements are involved (Uvell and Engstrom, 2007). Constitutively produced AMPs in Drosophila melanogaster have a wide spectrum of antimicrobial activity against bacteria and fungi as defensins, cecropin and drosocin are produced in the female reproductive tract or drosomycin is present in salivary glands, whereas expression of metchnikowin was detected only in the gastrointestinal tract (Bulet et al., 2004; Uvell and Engstrom, 2007).

The available literature indicates that many AMPs are expressed constitutively resulting in high AMP concentration in the intact insect, thus facilitating the commercial exploitation.

\section{Commercial development of insect AMPs}

Although natural proteins with antimicrobial activity have been known for decades, the possibility of using them in the feed industry is linked with various difficulties. The main limitation is related to the production cost. AMPs can be aquired as clean natural peptides, as peptides with a modified structure or as protein fractions. Both the production of the original peptides and modified peptides with antimicrobial activity is very difficult and expensive. The production of AMPs in recombinant bacterial cells like E. coli is not always successfull and may result in AMPs being inactive or even toxic to the bacterial cell (Hull et al., 2012). Nevertheless, it has been possible to produce some AMPs in this way, e.g., human $\beta$-defensin can be successfully produced in E. coli bacteria. The production of recombinant proteins against fungi in $E$. coli seems to be more effective (Hull et al., 2012).

Keeping the molecular and pharmacological data in mind, it seems reasonable to focus on small peptides in order to facilitate the commercial development of AMPs. There are several reasons for this. Generally, smaller AMPs are considered to be less toxic to eukaryotes, but potential toxicity is always a matter of concern and has to be evaluated. Further, smaller peptides are considered to be more stabile (McPhee et al., 2005). In order to even minimalize the toxicity, the introduction of unusual amino acids or modification of the terminal regions, e.g., through acetylation, can be considered. Further, the use of efficient medicine delivery systems like liposome encapsulation can be effective for the improvement of stability and reduction of potential toxicity (McPhee et al., 2005).

It counts in favour for insect AMPs, that those with the greatest activity are generally the smallest ones, which decreases the potential production cost (John et al., 2008; Seo et al., 2012).

\section{Dietary supplementation of insect AMPs}

Generally, insect AMPs have the same structures as other AMPs, for example those identified in mammals or in bacteria (bacteriocines), which have been successfully applied. The most explored bacteriocin is nisin, which is commonly used in many types of human foodstuffs as preservative and has also been added to animal feed as an anti-bacterial additive. It has been shown that the dietary supplementation of nisin reduced the numbers of Bacteroides and Enterobacteriacae in ileal digesta of broilers (Józefiak et al., 2013; Kierończyk et al., 2016). Another example may be lactoferrin derived from bovine milk, which is currently used as a nutritional supplement that can liberate active peptides from gastric digestion. It is able to reach the lower gastrointestinal tract and there excerts its effect. It has been shown that dietary supplementation with lactoferrin improves growth performance and reduces 
diarrhoea in pigs and decreases the counts of some potentially pathogenic gut bacteria as E. coli while increasing the numbers of potentially beneficial bacteria as lactobacilli and bifidobacteria (Yoon et al., 2012; Xiao et al., 2015a). Furthermore, it has been shown that the supplementation of pig diets with AMPs may increase villus height and crypt depth in the jejunum and ileum (Xiao et al., 2015a).

AMPs containing a simple peptide structure are presumed to be not absorbed from the ileum; they pass through the digestive system and reach bacteria to which they have affinity (Hancock and Chapple, 1999). Due to their ribosomal production, insect AMPs are based on natural amino acids (Anderson et al., 2016) and it may be expected that their effect in the animal digestive system is similar to that of nisin, having no systemic effects on the animal. Furthermore, due to their cationic nature, AMPs act preferentially on negatively charged cells such as microorganisms or cancer cells, whereas their effect on eukaryotic cells, which are positively charged, is limited. Therefore, their application may be regarded as safe.

Research on the effect of AMPs as dietary supplements in animal production has been conducted mainly on pigs (Tang et al., 2009, 2012; Yoon et al., 2012, 2013, 2014; Wu et al., 2012; Xiong et al., 2014). The analysed AMPs were, among others: antimicrobial peptide-A3 (AMP-A3), antimicrobial peptide-P5 (AMP-P5), antimicrobial peptide cecropin $\mathrm{AD}$, lactoferrins (cipB-lactoferricin-lactoferrampin, recombinant lactoferrampinlactoferricin), and the mixture of lactoferrin, cecropin, defensin and plectasin. In those researches the doses of single AMPs ranged from $40 \mathrm{mg} \cdot \mathrm{kg}^{-1}$ to $3 \mathrm{~g} \cdot \mathrm{kg}^{-1}$. The studies conducted by Yoon et al. $(2012,2013,2014)$ on the dietary supplementation of AMPs showed that both AMP-A3 and AMP-P5 (synthetic analogues of hybrid cecropin-magainin) have a positive effect on growth performance, faecal microbiota and intestinal morphology of weanling piglets. Cecropin is a type of antibacterial peptide identified in many insect species, while magainins are a class of antimicrobial peptides found in the African clawed frog (Xenopus laevis). In the studies of Yoon et al. $(2012,2013,2014)$, the basal diet was supplemented with 60 and $90 \mathrm{mg}$ of AMP-A3 or 40 and $60 \mathrm{mg}$ of AMP-P5 per $\mathrm{kg}$ of diet. The authors showed that the total number of anaerobic bacteria declined $(P<0.05)$ linearly with increasing levels of either AMP-A3 or AMP-P5 in the diets. Inhibited growth of coliforms and Clostridium spp. was observed in the ileum, caecum and faeces. Dietary treatment with AMP-A3 or AMP-P5 had no effect $(P>0.05)$ on the ileal apparent digestibility of amino acids and serum immunoglobulins (IgG, IgA, $\operatorname{IgM}$ ) concentration. However, in the duodenum and jejunum of pigs fed diets supplemented with AMPA3 or AMP-P5, the intestinal villi were higher and a greater villus height:crypt depth ratio was observed in comparison to pigs fed the negative control diet (Yoon et al., 2014). Moreover, increasing levels of dietary AMP linearly improved the overall average daily gain and the total tract apparent digestibility of crude protein, dry matter and gross energy (Yoon et al., 2012, 2014). Similar effects for AMP-P5 were obtained following supplementation of piglet diets (Yoon et al., 2013). The authors suggest that AMPP5 at dietary concentrations of $60 \mathrm{mg} \cdot \mathrm{kg}^{-1}$ may be used as a novel alternative to antibiotic growth promoters. The same beneficial effects of the AMP-A3 and AMP-P5 on growth performance were reported from experiments with broilers (Choi et al., 2013a,b; Wang et al., 2016).

The addition of synthetic cecropin to broiler diets decreased aerobic bacterial counts in jejunal and caecal digesta in a dose-dependent manner (Wen and $\mathrm{He}, 2012$ ) and enhanced intestinal villus height in the duodenum. Therefore, the authors suggest cecropin as possible alternative to antibiotic growth promoter in broiler production.

The dietary supplementation of weaning piglets with lactoferrin in concentrations of $1 \mathrm{~g} \cdot \mathrm{kg}^{-1}$ feed inhibited the growth of coliforms and Clostridium spp., and reduced the total counts of pathogenic microbiota such as E. coli and Salmonella $(P<0.05)$, and increased potentially beneficial microorganisms such as Lactobacillus and Bifidobacterium in the small intestine (Wang et al., 2007).

In an in vivo study performed on weaned piglets from commercial farms, an AMP complex providing a mixture of lactoferrin, cecropin, defensin and plectasin ( $2 \mathrm{~g}$ and $3 \mathrm{~g} \cdot \mathrm{kg}^{-1}$ feed), improved growth performance, reduced the incidence of diarrhoea and increased the survival rate of weaned pigs in comparison to non-treated ones (Xiong et al., 2014). Results obtainened in vitro suggest that compounds containing insect AMP complexes have an advantage over individual peptide and small molecule antibiotics (Chernysh et al., 2015). In line with this, the application of insect meal providing a variety of different AMPs as a supplement to animal feed may give rise to new possibilities in animal production. An interesting solution in animal production could be the dietary supplementation with the active antimicrobial fraction of proteins extracted from dried full fat insect meal. 


\section{Conclusions}

Studies on antimicrobial peptides (AMPs) and their applications have become one of the hot topics in the areas of agricultural science, biology, human and veterinary medicine and the food and feed industries. Antimicrobial peptides provide great hope due to the global problem related to the increasing resistance of bacteria to antibiotics. The mechanism of insect AMPs actions has been shaped over hundreds of years of evolution, and it is very conservative, suggesting the risk of bacterial resistance to be low. Moreover, bactericidal insect AMPs may also protect organism against viruses and fungi. Further, they have to be considered as immune modulators and may even be a hope for cancer therapy having lower adverse side effects. Currently, no insect derived AMPs have been introduced on the market yet. However, according to the available literature, insects have the potential to be a good source of AMPs, which may be exploited as alternative to antibiotics in livestock production, including the support of animal growth and health, treatment of infections and in the preservation of food. However, much work has still to be done to facilitate large scale production of insect AMPs and to find ways for their efficient application in livestock.

\section{References}

Aerts A.M., François I.E.J.A., Cammue B.P.A., Thevissen K., 2008. The mode of antifungal action of plant, insect and human defensins. Cell. Mol. Life Sci. 65, 2069-2079, https://doi.org/10.1007/ s00018-008-8035-0

Andersen A.S., Sandvang D., Schnorr K.M., Kruse T., Neve S., Joergensen B., Karlsmark T., Krogfelt K.A., 2010. A novel approach to the antimicrobial activity of maggot debridement therapy. J. Antimicrob. Chemother. 65, 1646-1654, https://doi. org/10.1093/jac/dkq165

Andersson D.I., Hughes D., Kubicek-Sutherland J.Z., 2016. Mechanisms and consequences of bacterial resistance to antimicrobial peptides. Drug Resist. Updates 26, 43-57, https://doi. org/10.1016/j.drup.2016.04.002

Bagnicka E., JóźwikA., Strzałkowska N., Krzyżewski J., Zwierzchowski L., 2011. Antimicrobial peptides - outline of the history of studies and mode of action (in Polish). Med. Wet. 67, 444-448

Bengoechea J.A., Skurnik M., 2000. Temperature-regulated efflux pump/ potassium antiporter system mediates resistance to cationic antimicrobial peptides in Yersinia. Mol. Microbiol. 37, 67-80, https://doi.org/10.1046/j.1365-2958.2000.01956.x

Boman H.G., Nilsson-Faye I., Paul K., Rasmuson T. Jr, 1974. Insect immunity. I. Characteristics of an inducible cell-free antibacteria reaction in hemolymph of Samia cynthia pupae. Infect. Immun. $10,136-145$

Bovera F., Loponte R., Marono S., Piccolo G., Parisi G., laconisi V., Gasco L., Nizza A., 2016. Use of Tenebrio molitor larvae meal as protein source in broiler diet: Effect on growth performance, nutrient digestibility, and carcass and meat traits. J. Anim. Sci. 94, 639-647, https://doi.org/10.2527/jas.2015-9201
Buchon N., Silverman N., Cherry S., 2014. Immunity in Drosophila melanogaster - from microbial recognition to whole-organism physiology. Nat. Rev. Immunol. 14, 796-810, https://doi.org/10.1038/ nri3763

Bulet P., Stöcklin R., 2005. Insect antimicrobial peptides: structures, properties and gene regulation. Protein Pept. Lett. 12, 3-11, https://doi.org/10.2174/0929866053406011

Bulet P., Stöcklin R., Menin L., 2004. Anti-microbial peptides: from invertebrates to vertebrates. Immunol. Rev. 198, 169-184, https://doi.org/10.1111/j.0105-2896.2004.0124.x

Cheng J.-x., Liu Y.-g., Suo W.-I., Zhao R.-j., Fan H.-y., 2010. Effects of the antimicrobial peptide of Tenebrio molitor Linnaeus on cell cycle of K562 and inhibitory effects of that on cell proliferation compared with hydroxyurea. Chin. J. Vector Biol. Control 21, 324-326

Chernysh S., Gordya N., Suborova T., 2015. Insect antimicrobial peptide complexes prevent resistance development in bacteria. PLoS ONE 10, e0130788, https://doi.org/10.1371/journal. pone. 0130788

Choi S.C., Ingale S.L., Kim J.S., Park Y.K., Kwon I.K., Chae B.J., 2013a. Effects of dietary supplementation with an antimicrobial peptide-P5 on growth performance, nutrient retention, excreta and intestinal microflora and intestinal morphology of broilers. Anim. Feed Sci. Technol. 185, 78-84, https://doi.org/10.1016/j.anifeedsci.2013.07.005

Choi S.C., Ingale S.L., Kim J.S., Park Y.K., Kwon I.K., Chae B.J., $2013 b$. An antimicrobial peptide-A3: effects on growth performance, nutrient retention, intestinal and faecal microflora and intestinal morphology of broilers. Br. Poult. Sci. 54, 738-746, https://doi. org/10.1080/00071668.2013.838746

Choi W.-H., Yun J.-H., Chu J.-P., Chu K.-B., 2012. Antibacterial effect of extracts of Hermetia illucens (Diptera: Stratiomyidae) larvae against Gram-negative bacteria. Entomol. Res. 42, 219-226, https://doi.org/10.1111/j.1748-5967.2012.00465.x

Coyne L.A., Latham S.M., Williams N.J., Dawson S., Donald I.J., Pearson R.B., Smith R.F., Pinchbeck G.L., 2016. Understanding the culture of antimicrobial prescribing in agriculture: a qualitative study of UK pig veterinary surgeons. J. Antimicrob. Chemother. 71, 3300-3312, https://doi.org/10.1093/jac/dkw300

Dang X.L., Wang Y.S., Huang Y.D., Yu X.Q., Zhang W.Q., 2010. Purification and characterization of an antimicrobial peptide, insect defensin, from immunized house fly (Diptera: Muscidae). J. Med. Entomol. 47, 1141-1145, https://doi.org/10.1603/ME10016

Duclohier H., 2002. How do channel- and pore-forming helical peptides interact with lipid membranes and how does this account for their antimicrobial activity? Mini-Rev. Med. Chem. 2, 331-342, https://doi.org/10.2174/1389557023405963

El-Tantawy N.L., 2015. Helminthes and insects: maladies or therapies. Parasitol. Res. 114, 359-377, https://doi.org/10.1007/s00436014-4260-7

Erickson M.C., Islam M., Sheppard C., Liao J., Doyle M.P., 2004. Reduction of Escherichia coli 0157:H7 and Salmonella enterica serovar Enteritidis in chicken manure by larvae of the black soldier fly. J. Food Prot. 67, 685-690, https://doi.org/10.4315/0362028X-67.4.685

Faye I., Pye A., Rasmuson T., Boman H.G., Boman I.A., 1975. Insect immunity: II. Simultaneous induction of antibacterial activity and selective synthesis of some haemolymph proteins in diapausing pupae of Hyalophora cecropia and Samia cynthia. Infect. Immun. 12, 1426-1438

Frick I.-M., Åkesson P., Rasmussen M., Schmidtchen A., Björck L., 2003. SIC, a secreted protein of Streptococcus pyogenes that inactivates antibacterial peptides. J. Biol. Chem. 278, 16561-16566, https://doi.org/10.1074/jbc.M301995200 
Fu P., Wu J., Guo G., 2009. Purification and molecular identification of an antifungal peptide from the hemolymph of Musca domestica (housefly). Cell. Mol. Immunol. 6, 245-251, https://doi. org/10.1038/cmi.2009.33

Groisman E.A., Parra-Lopez C., Salcedo M., Lipps C.J., Heffron F., 1992. Resistance to host antimicrobial peptides is necessary for Salmonella virulence. Proc. Natl. Acad. Sci. USA 89, 11939-11943, https://doi.org/10.1073/pnas.89.24.11939

Guina T., Yi E.C., Wang H., Hackett M., Miller S.I., 2000. A PhoPregulated outer membrane protease of Salmonella enterica serovar typhimurium promotes resistance to alpha-helical antimicrobial peptides. J. Bacteriol. 182, 4077-4086, https://doi. org/10.1128/JB.182.14.4077-4086.2000

Hancock R.E.W., Chapple D.S., 1999. Peptide antibiotics. Antimicrob. Agents Chemother. 43, 1317-1323

Hansen A., Schäfer I., Knappe D., Seibel P., Hoffmann R., 2012. Intracellular toxicity of proline-rich antimicrobial peptides shuttled into mammalian cells by the cell-penetrating peptide penetration. Antimicrob. Agents Chemother. 56, 5194-5201, https://doi.org/10.1128/AAC.00585-12

Hull R., Katete R., Ntwasa M., 2012. Therapeutic potential of antimicrobial peptides from insects. Biotechnol. Mol. Biol. Rev. 7, 31-47

Hultmark D., Steiner H., Rasmuson T., Boman H.G., 1980. Insect immunity. Purification and properties of three inducible bactericidal proteins from hemolymph of immunized pupae of Hyalophora cecropia. Eur. J. Biochem. 106, 7-16, https://doi. org/10.1111/j.1432-1033.1980.tb05991.x

Imler J.-L., Hoffmann J.A., 2000. Signaling mechanisms in the antimicrobial host defense of Drosophila. Curr. Opin. Microbiol. 3 , 16-22, https://doi.org/10.1016/S1369-5274(99)00045-4

Jin T., Bokarewa M., Foster T., Mitchell J., Higgins J., Tarkowski A., 2004. Staphylococcus aureus resists human defensins by production of staphylokinase, a novel bacterial evasion mechanism. J. Immunol. 172, 1169-1176, https://doi.org/10.4049/ jimmunol.172.2.1169

John H., Maronde E., Forssmann W.G., Meyer M., Adermann K., 2008. N-terminal acetylation protects glucagon-like peptide GLP-1-(7-34)-amide from DPP-IV-mediated degradation retaining CAMP- and insulin-releasing capacity. Eur. J. Med. Res. 13, 73-78

Jones D.E., Bevins C.L., 1992. Paneth cells of the human small intestine express an antimicrobial peptide gene. J. Biol. Chem. 267, 23216-23225

Joo H.-S., Fu C.-I., Otto M., 2016. Bacterial strategies of resistance to antimicrobial peptides. Philos. Trans. R. Soc. B-Biol. Sci. 371, 20150292, https://doi.org/10.1098/rstb.2015.0292

Józefiak D., Józefiak A., Kierończyk B., Rawski M., Świątkiewicz S., Długosz J., Engberg R.M., 2016. Insects - a natural nutrient source for poultry - a review. Ann. Anim. Sci. 16, 297-313, https://doi.org/10.1515/aoas-2016-0010

Józefiak D., Kierończyk B., Juśkiewicz J., Zduńczyk Z., Rawski M., Długosz J., Sip A., Højberg O., 2013. Dietary nisin modulates the gastrointestinal microbial ecology and enhances growth performance of the broiler chickens. PLoS ONE 8, e85347, https://doi.org/10.1371/journal.pone.0085347

Kierończyk B., Pruszyńska-Oszmałek E., Świątkiewicz S., Rawski M., Długosz J., Engberg R.M., Józefiak D., 2016. The nisin improves broiler chicken growth performance and interacts with salinomycin in terms of gastrointestinal tract microbiota composition. J. Anim. Feed Sci. 25, 309-316, https://doi. org/10.22358/jafs/67802/2016
Kim I.-W., Lee J.H., Subramaniyam S., Yun E.-Y., Kim I., Park J., Hwang J.S., 2016. De novo transcriptome analysis and detection of antimicrobial peptides of the American cockroach Periplaneta americana (Linnaeus). PLoS ONE, 11, e0155304, https://doi.org/10.1371/journal.pone.0155304

Kragol G., Hoffmann R., Chattergoon M.A., Lovas S., Cudic M., Bulet P., Condie B.A., Rosengren K.J., Montaner L.J., Otvos L. Jr, 2002. Identification of crucial residues for the antibacterial activity of the proline-rich peptide, pyrrhocoricin. Eur. J. Biochem. 269, 4226-4237, https://doi.org/10.1046/ j.1432-1033.2002.03119.x

Lamberty M., Zachary D., Lanot R., Bordereau C., Robert A., Hoffmann J.A., Bulet P., 2001. Inect immunity. Constitutive expression of a cysteine-rich antifungal and a linear antibacterial peptide in a termite insect. J. Biol. Chem. 276, 4085-4092, https://doi.org/10.1074/jbc.M002998200

Landers T.F., Cohen B., Wittum T.E., Larson E.L., 2012. A review of antibiotic use in food animals: perspective, policy, and potential. Public Health Rep. 127, 4-22

Lee K.H., Hong S.Y., Oh J.E., 1998. Synthesis and structure-function study about tenecin 1 , an antibacterial protein from larvae of Tenebrio molitor. FEBS Lett. 439, 41-45, https://doi. org/10.1016/S0014-5793(98)01333-7

Lee S., Siddiqui R., Khan N.A., 2012. Animals living in polluted environments are potential source of antimicrobials against infectious agents. Pathog. Glob. Health 106, 218-223, https://doi.org/10.1179/2047773212Y.0000000033

Lee Y.-T., Kim D.-H., Suh J.-Y., Chung J.H., Lee B.L., Lee Y., Choi B.-S., 1999. Structural characteristics of tenecin 3, an insect antifungal protein. IUBMB Life 47, 369-376, https://doi. org/10.1080/15216549900201393 Lehrer R.I., Ganz T., 1990. Antimicrobial polypeptides of human neutrophils. Blood 76, 2169-2181

Li W.-F., Ma G.-X., Zhou X.-X., 2006. Apidaecin-type peptides: Biodiversity, structure-function relationships and mode of action. Peptides 27, 2350-2359, https://doi.org/10.1016/j.peptides.2006.03.016

Li Y., Xiang Q., Zhang Q., Huang Y., Su Z., 2012. Overview on the recent study of antimicrobial peptides: Origins, functions, relative mechanisms and application. Peptides 37, 207-215, https://doi.org/10.1016/j.peptides.2012.07.001

Luenser K., Ludwig A., 2005. Variability and evolution of bovine $\beta$-defensin genes. Genes Immun. 6, 115-122, https://doi. org/10.1038/sj.gene.6364153

Makkar H.P.S., Tran G., Heuzé V., Ankers P., 2014. State-of-the-art on use of insects as animal feed. Anim. Feed Sci. Technol. 197, 1-33, https://doi.org/10.1016/j.anifeedsci.2014.07.008

Mattiuzzo M., Bandiera A., Gennaro R., Benincasa M., Pacor S., Antcheva N., Scocchi M., 2007. Role of the Escherichia coli SbmA in the antimicrobial activity of proline-rich peptides. Mol. Microbiol. 66, 151-163, https://doi.org/10.1111/j.13652958.2007.05903.x

McCoy A.J., Liu H., Falla T.J., Gunn J.S., 2001. Identification of Proteus mirabilis mutants with increased sensitivity to antimicrobial peptides. Antimicrob. Agents Chemother. 45, 2030-2037, https://doi.org/10.1128/AAC.45.7.2030-2037.2001

McPhee J.B., Scott M.G., Hancock R.E.W., 2005. Design of host defence peptides for antimicrobial and immunity enhancing activities. Comb. Chem. High Throughput Screen 8, 257-272, https://doi.org/10.2174/1386207053764558

Narayanan S., Modak J.K., Ryan C.S., Garcia-Bustos J., Davies J.K., Roujeinikova A., 2014. Mechanism of Escherichia coli resistance to pyrrhocoricin. Antimicrob. Agents Chemother. 58, 2754-2762, https://doi.org/10.1128/AAC.02565-13 
Nicolas P., 2009. Multifunctional host defence peptides: intracellulartargeting antimicrobial peptides. FEBS J. 276, 6483-6496, https://doi.org/10.1111/j.1742-4658.2009.07359.x

Ouellette A.J., Darmoul D., Tran D., Huttner K.M., Yuan J., Selsted M.E., 1999. Peptide localization and gene structure of cryptdin 4 , a differentially expressed mouse paneth cell $a$-defensin. Infect. Immun. 67, 6643-6651

Park S.-I., Chang B.S., Yoe S.M., 2014. Detection of antimicrobial substances from larvae of the black soldier fly, Hermetia illucens (Diptera: Stratiomyidae). Entomol. Res. 44, 58-64, https:// doi.org/10.1111/1748-5967.12050

Park S.-I., Kim J.-W., Yoe S.M., 2015. Purification and characterization of a novel antibacterial peptide from black soldier fly (Hermetia illucens) larvae. Dev. Comp. Immunol. 52, 98-106, https:// doi.org/10.1016/j.dci.2015.04.018

Park Y., Hahm K.-S., 2005. Antimicrobial peptides (AMPs): peptide structure and mode of action. J. Biochem. Mol. Biol. 38, 507-516, https://doi.org/10.5483/bmbrep.2005.38.5.507

Peschel A., Vuong C., Otto M., Götz F., 2000. The D-alanine residues of Staphylococcus aureus teichoic acids alter the susceptibility to vancomycin and the activity of autolytic enzymes. Antomicrob. Agents Chemother. 44, 2845-2847, https://doi. org/10.1128/AAC.44.10.2845-2847.2000

Ratcliffe N.A., Mello C.B., Garcia E.S., Butt T.M., Azambuja P., 2011. Insect natural products and processes: New treatments for human disease. Insect Biochem. Mol. Biol. 41, 747-769, https://doi.org/10.1016/j.ibmb.2011.05.007

Rodríguez-Rojas A., Makarova O., Rolff J., 2014. Antimicrobials, stress and mutagenesis. PLoS Pathog. 10, e1004445, https:// doi.org/10.1371/journal.ppat.1004445

Rotem S., MorA., 2009. Antimicrobial peptide mimics for improved therapeutic properties. Biochim. Biophys. Acta-Biomembr. 178, 1582-1592, https://doi.org/10.1016/j.bbamem.2008.10.020

Sánchez-Muros M.J., Barroso F.G., Manzano-Agugliaro F., 2014. Insect meal as renewable source of food for animal feeding: a review. J. Clean. Prod. 65, 16-27, https://doi.org/10.1016/j. jclepro.2013.11.068

Schiappa J., Van Hee R., 2012. From ants to staples: history and ideas concerning suturing techniques. Acta Chir. Belg. 2012, 112, 395-402, https://doi.org/10.1080/00015458.2012.11680861

Seo M.-D., Won H.-S., Kim J.-H., Mishig-Ochir T., Lee B.-J., 2012. Antimicrobial peptides for therapeutic applications: a review. Molecules 17, 12276-12286, https://doi.org/10.3390/molecules171012276

Shafer W.M., Qu X.-D., Waring A.J., Lehrer R.I., 1998. Modulation of Neisseria gonorrhoeae susceptibility to vertebrate antibacterial peptides due to a member of the resistance/nodulation/ division efflux pump family. Proc. Natl. Acad. Sci. USA 95, 1829-1833, https://doi.org/10.1073/pnas.95.4.1829

Steiner H., Hultmark D., Engström A., Bennich H., Boman H.G., 1981. Sequence and specificity of two antibacterial proteins involved in insect immunity. Nature 292, 246-248, https://doi. org/10.1038/292246a0

Stumpe S., Schmid R., Stephens D.L., Georgiou G., Bakker E.P., 1998. Identification of OmpT as the protease that hydrolyzes the antimicrobial peptide protamine before it enters growing cells of Escherichia coli. J. Bacteriol. 180, 4002-4006

Sun H.-X., Chen L.-Q., Zhang J., Chen F.-Y., 2014. Anti-tumor and immunomodulatory activity of peptide fraction from the larvae of Musca domestica. J. Ethnopharmacol. 153, 831-839, https:// doi.org/10.1016/j.jep.2014.03.052
Tang X., Fatufe A.A., Yin Y., Tang Z., Wang S., Liu Z., Xinwu, Li T.-J., 2012. Dietary supplementation with recombinant lactoferrampin-lactoferricin improves growth performance and affects serum parameters in piglets. J. Anim. Vet. Adv. 11, 2548-2555, https://doi.org/10.3923/javaa.2012.2548.2555

Tang Z., Yin Y., Zhang Y. et al., 2009. Effects of dietary supplementation with an expressed fusion peptide bovine lactoferricin-lactoferrampin on performance, immune function and intestinal mucosal morphology in piglets weaned at age 21 d. Br. J. Nutr. 101, 998-1005, https://doi.org/10.1017/ S0007114508055633

Uvell H., Engström Y., 2007. A multilayed defense against infection: combinatorial control of insect immune genes. Trends Genet. 23, 342-349, https://doi.org/10.1016/j.tig.2007.05.003

Wang S., Zeng X., Yang Q., Qiao S., 2016. Antimicrobial peptides as potential alternatives to antibiotics in food animal industry. Int. J. Mol. Sci. 17, 603-614, https://doi.org/10.3390/ ijms17050603

Wang Y.-Z., Shan T.-Z., Xu Z.-R., Feng J., Wang Z.-Q., 2007. Effects of the lactoferrin (LF) on the growth performance, intestinal microflora and morphology of weanling pigs. Anim. Feed Sci. Technol. 135, 263-272, https://doi.org/10.1016/j.anifeedsci.2006.07.013

Wen L.-F., He J.-G., 2012. Dose-response effects of an antimicrobial peptide, a cecropin hybrid, on growth performance, nutrient utilisation, bacterial counts in the digesta and intestinal morphology in broilers. Br. J. Nutr. 108, 1756-1763, https://doi. org/10.1017/S0007114511007240

Wu S., Zhang F., Huang Z., Liu H., Xie C., Zhang J., Thacker P.A., Qiao S., 2012. Effects of the antimicrobial peptide cecropin $A D$ on performance and intestinal health in weaned piglets challenged with Escherichia coli. Peptides 35, 225-230, https://doi.org/10.1016/j.peptides.2012.03.030

Xiao H., Shao F., Wu M., Ren W., Xiong X., Tan B., Yin Y., 2015a. The application of antimicrobial peptides as growth and health promoters for swine. J. Anim. Sci. Biotechnol. 6, 19, https:// doi.org/10.1186/s40104-015-0018-z

Xiao H., Tan B.E., Wu M.M., Yin Y.L., Li T.J., Yuan D.X., Li L., $2013 a$. Effects of composite antimicrobial peptides in weanling piglets challenged with deoxynivalenol: II. Intestinal morphology and function. J. Anim. Sci. 91, 4750-4756, https://doi. org/10.2527/jas.2013-6427

Xiao H., Wu M.M., Shao F.Y. et al., 2015b. Metabolic profiles in the response to supplementation with composite antimicrobial peptides in piglets challenged with deoxynivalenol. J. Anim. Sci. 93, 1114-1123, https://doi.org/10.2527/ jas.2014-8229

Xiao H., Wu M.M., Tan B.E., Yin Y.L., Li T.J., Xiao D.F., Li L., 2013b. Effects of composite antimicrobial peptides in weanling piglets challenged with deoxynivalenol: I. Growth performance, immune function, and antioxidation capacity. J. Anim. Sci. 91, 4772-4780, https://doi.org/10.2527/jas.2013-6426

Xiong X., Yang H.S., Li L., Wang Y.F., Huang R.L., Li F.N., Wang S.P., Qiu W., 2014. Effects of antimicrobial peptides in nursery diets on growth performance of pigs reared on five different farms. Livest. Sci. 167, 206-210, https://doi.org/10.1016/j. livsci.2014.04.024

Yi H.-Y., Chowdhury M., Huang Y.-D., Yu X.-Q., 2014. Insect antimicrobial peptides and their applications. Appl. Microbiol. Biotechnol. 98, 5807-5822, https://doi.org/10.1007/s00253014-5792-6 
Yoon J.H., Ingale S.L., Kim J.S., Kim K.H., Lee S.H., Park Y.K., Kwon I.K., Chae B.J., 2012. Effects of dietary supplementation of antimicrobial peptide-A3 on growth performance, nutrient digestibility, intestinal and fecal microflora and intestinal morphology in weanling pigs. Anim. Feed Sci. Technol. 177, 98-107, https://doi.org/10.1016/j.anifeedsci.2012.06.009

Yoon J.H., Ingale S.L., Kim J.S., Kim K.H., Lee S.H., Park Y.K., Lee S.C., Kwon I.K., Chae B.J., 2014. Effects of dietary supplementation of synthetic antimicrobial peptide-A3 and P5 on growth performance, apparent total tract digestibility of nutrients, fecal and intestinal microflora and intestinal morphology in weanling pigs. Livest. Sci. 159, 53-60, https://doi.org/10.1016/j. livsci.2013.10.025
Yoon J.H., Ingale S.L., Kim J.S., Kim K.H., Lohakare J., Park Y.K., Park J.C., Kwon I.K., Chae B.J., 2013. Effects of dietary supplementation with antimicrobial peptide-P5 on growth performance, apparent total tract digestibility, faecal and intestinal microflora and intestinal morphology of weanling pigs. J. Sci. Food Agric. 93, 587-592, https://doi.org/10.1002/jsfa.5840

Żyłowska M., Wyszyńska A., Jagusztyn-Krynicka E.K., 2011. Antimicrobial peptides - defensins (in Polish). Post. Mikrobiol. 50 223-234 